\title{
PENGGUNAAN MEDIA PEMBELAJARAN POSTER DI BENGKEL
}

\author{
Indah Wahyuni ${ }^{1}$, Nur Hidayat ${ }^{2}$ \\ ${ }_{1,2}$ Pendidikan Teknik Sipil dan Perencanaan, FT, UNY \\ Email: indahwahyuni@uny.ac.id
}

\begin{abstract}
This study is aimed to determine: (1) the use of posters as a medium of learning at the workshop of Education Department of Civil Engineering and Planning FT UNY, (2) requirements in making posters as instructional media, and (3) Correspondence between poster as a learning media with the workshop at Department of Education of Civil Engineering and Planning FT UNY. This study Applies a descriptive approach (descriptive research). In this study, the researchers did not provide any treatment to what is observed however only describes in detail merely to what was found in the data collection. The findings of this study are (1) poster has been used as a medium of learning both in carpentry, plumbing workshop, and rock workshop. Poster is used to convey information such as personal protective equipment, work step, parts of an instrument, learning products, and K3 (2) the factors of the preconditions if poster at carpentry and rock workshop have been fulfilled. However the preconditions the form of size and color of poster at the plumbing workshop still need to be resized. In addition, the suitability factors such as ease of posters indicators in order to be easily seen in carpentry and plumbing workshop also need to be resized. Other indicators contained in preconditions factors such as expediency and suitability in the third workshop have been fulfilled. (3) The compliance of poster in carpentry, plumbing workshop, and rock workshop at the Education Department of Civil Engineering and Planning FT UNY is good. Posters are suitable to the function and purpose of each workshop. They only need resizing and repositioning.
\end{abstract}

Keywords: instructional media, posters, workshop

\begin{abstract}
ABSTRAK
Penelitian ini bertujuan untuk mengetahui: (1) penggunaan poster sebagai media pembelajaran di bengkel Jurusan Pendidikan Teknik Sipil dan Perencanaan FT UNY (2) persyaratan dalam pembuatan poster sebagai media pembelajaran (3) Kesesuaian antara media pembelajaran poster dengan bengkel di Jurusan Pendidikan Teknik Sipil dan Perencanaan FT UNY. Penelitian ini menggunaan pendekatan deskriptif(descriptive reasearch). Dalam penelitian ini, peneliti tidak memberikan perlakuan terhadap apa yang diteliti tetapi hanya sebatas mendeskripsikan secara detail terhadap apa yang ditemukan dalam pengambilan data. Hasil penelitian ini adalah (1) Poster telah dimanfaatkan sebagai media pembelajaran baik di bengkel kayu, bengkel plambing, maupun bengkel batu. Poster digunakan untuk menyampaikan informasi alat pelindung diri, langkah kerja, bagian-bagian dari suatu alat, produk pembelajaran, maupun K3 (2) Faktor prasyarat poster di bengkel kayu dan bengkel batu sudah terpenuhi. Hanya saja untuk prasyarat berupa indikator ukuran dan warna poster di bengkel plambing masih perlu ditingkatkan. Selain itu, faktor kesesuaian berupa indikator kemudahan poster untuk terlihat di bengkel kayu dan plambing juga perlu ditingkatkan. Indikator lain yang terdapat pada faktor prasyarat, kemanfaatan, dan kesesuaian di ketiga bengkel tersebut sudah terpenuhi (3) Kesesuaian poster di bengkel kayu, bengkel plambing, dan bengkel batu di Jurusan Pendidikan Teknik Sipil dan Perencanaan FT UNY sudah baik. Poster sudah sesuai dengan fungsi dan maksud masing-masing bengkel. Hanya saja perlu adanya pembenahan dalam penempatan poster.
\end{abstract}

Kata kunci: media pembelajaran, poster, bengkel

\section{PENDAHULUAN}

Tim Pengembang Media Pembelajaran dan TI (2015) berpendapat, salah satu capaian pembelajaran mata kuliah Media Pembelajaran dan Teknologi Informasi di Jurusan Pendidikan
Teknik Sipil dan Perencanaan FT UNY adalah menerapkan konsep pengembangan ragam media pembelajaran dua dimensi [1]. Salah satu bahan kajian dalam capaian pembelajaran tersebut adalah mendesain ragam poster atau wallchart. Mahasiswa harus mampu 
mengidentifikasi unsur-unsur desain poster atau wallchart serta mampu membuatnya. Poster yang digunakan sebagai media atau perantara dapat digunakan untuk menyampaikan pesan baik secara umum maupun secara khusus dalam pembelajaran. Pembuatan poster sebagai bahan ajar tersebut dapat dikaitkan dengan berbagai mata kuliah di Jurusan Pendidikan Teknik Sipil dan Perencanaan maupun mata pelajaran di Sekolah Menengah Kejuruan (SMK). Selain itu, poster juga dapat digunakan sebagai media pembelajaran di lingkungan Jurusan Pendidikan Teknik Sipil dan Perencanaan termasuk salah satunya bengkel.

Jurusan Pendidikan Teknik Sipil dan Perencanaan FT UNY mempunyai tiga bengkel yang digunakan sebagai tempat praktik mahasiswa, yaitu: bengkel plambing, bengkel kayu, dan bengkel batu. Di bengkel-bengkel tersebut terdapat berbagai macam aspek apabila dikaitkan dengan poster, diantaranya Kesehatan dan Keselamatan Kerja (K3), peralatan, bahan, produk, langkah kerja, dan lain sebagainya. Poster yang terdapat di bengkel pada umumnya sudah usang. Warna poster tersebut sudah pudar sehingga kurang menarik. Syarat poster yang menarik sudah tidak dapat terpenuhi dengan keadaan ini. Selain itu, poster sebagai media pembelajaran juga belum dimanfaatkan secara maksimal di bengkel. Pembuatan poster oleh mahasiswa belum sesuai dengan keadaan nyata di bengkel karena dari ketiga bengkel yang terdapat di Jurusan Pendidikan Teknik Sipil dan Perencanaan mempunyai karakteristik yang berbeda-beda. Poster peralatan praktik masih tercampur diantara ketiga bengkel yang ada. Poster peralatan tersebut seharusnya sudah spesifik untuk setiap bengkel. Sedangkan dalam kasus lain, terdapat poster di bengkel yang dalam pembuatannya belum memenuhi unsur-unsur poster. Poster sebagai media pembelajaran hendaknya harus sesuai dengan unsur-unsur yang disyaratkan.

Oleh karena masalah-masalah seperti diatas yang khususnya terkait dengan poster hendaknya dapat diatasi agar dalam pemanfaatannya dapat maksimal. Poster diharapkan dapat dijadikan sebagai media penyampai informasi yang baik. Selain itu, dalam pembuatannya diharapkan mahasiswa mampu memenuhi unsur-unsur poster yang disyaratkan. Hal tersebut terkait penggunaan poster sebagai media pembelajaran. Terkait latar belakang diatas dapat diidentifikasi permasalahan: (1) Sudah usangnya media pembelajaran poster yang terdapat di bengkel. (2) Dalam pemanfaatannya, pembuatan poster sebagai salah satu tugas mata kuliah Media Pembelajaran dan Teknologi Informasi kurang maksimal. (3) Kurang menariknya media poster yang terdapat di bengkel. (4) Pembuatan media pembelajaran poster yang belum disesuaikan dengan lokasi. (5) Pembuatan media pembelajaran poster yang belum sesuai dengan persyaratan maupun unsur-unsur desainnya. Peneliti membatasi masalah agar dalam pelaksanaan penelitian dapat fokus dan mendalam. Peneliti mengamati pemanfaatan poster sebagai media pembelajaran terutama di bengkel Jurusan Pendidikan Teknik Sipil dan Perencanaan FT UNY.

Penelitian ini bertujuan untuk mengetahui: (1) Penggunaan poster sebagai media pembelajaran di bengkel Jurusan Pendidikan Teknik Sipil dan Perencanaan FT UNY. (2) Persyaratan dalam pembuatan poster sebagai media pembelajaran. (3) Kesesuaian antara media pembelajaran poster dengan bengkel di Jurusan Pendidikan Teknik Sipil dan Perencana-an FT UNY. Peneliti mengartikan beberapa istilah sebagai berikut: (1) Media pembelajaran yaitu perantara informasi yang digunakan dalam kegiatan pembelajaran. (2) Poster yaitu gambar, tulisan, atau gambar dan tulisan dua dimensi yang digunakan sebagai media penyampai informasi. (3) Bengkel yaitu ruang atau lokasi kuliah untuk praktik plambing, kayu, dan batu. Selain itu, peneliti juga memberikan deskripsi dari variabel penelitan sebagai berikut. 
Pembelajaran merupakan hal yang tidak terpisahkan dari dunia pendidikan termasuk di Jurusan Pendidikan Teknik Sipil dan Perencanaan FT UNY. Dalam pembelajaran diperlukan suatu media sebagai perantara untuk menyampaikan informasi. Proses pembelajaran beserta media yang digunakan tersebut dipelajari di mata kuliah Media Pendidikan dan Teknologi Informasi. Dalam mata kuliah tersebut dibahas mengenai proses pembelajaran dan penggunaan media. Media yang digunakan salah satunya adalah poster. Hendriyadi, Madewi, dan Mitarlis (2014) menyatakan bahwa pembelajaran dengan model kooperatif tipe Student Team Achievement Divisions (STAD) menggunakan media poster mendapatkan respon positif dari siswa[2]. Sedangkan I Putu, Arwin, dan Berti (2015) menyatakan bahwa penggunaan poster melalui model pembelajaran kooperatif Student Team Achievement Divisions (STAD) memberikan peningkatan aktivitas siswa yang sangat tinggi [3]. Sementara itu Hanif (2014) menyatakan bahwa perencanaan pembelajaran IPS dengan menggunakan media poster membantu dapat meningkatkan kemampuan berfikir kreatif, selain itu keaktifan siswa lebih terlihat dalam proses pembelajaran[4].

Menurut Bretz (1971) media dibagi menjadi tiga unsur, yaitu unsur: suara, visual, dan gerak. Media visual sendiri dibedakan menjadi tiga, yaitu: gambar, garis, dan simbol yang merupakan suatu bentuk sehingga dapat ditangkap dengan indera penglihatan [5]. Poster merupakan salah satu media yang digunakan dalam pembelajaran. Media tersebut digunakan untuk berbagai kepentingan termasuk untuk menyampaikan informasi. Desain dan pembuatan poster harus sesuai dengan unsurunsur yang disyaratkan. Penggunaan poster sebagai media dalam pembelajaran di Jurusan Pendidikan Teknik Sipil dan Perencanaan FT UNY salah satunya sebagai media di bengkel, baik untuk menjelaskan peralatan, bahan, langkah kerja, perawatan, dan lain sebagainya. Hanya saja, poster yang terdapat di bengkel- bengkel tersebut secara umum sudah mulai usang sehingga perlu perbaikan.

\section{METODE}

Peneliti berusaha mengkaji secara ilmiah mengenai pemanfaatan media pembelajaran poster yang menjadi salah satu tugas mata kuliah Media Pembelajaran dan Teknologi Informasi oleh mahasiswa semester V. Tugas tersebut dimanfaatkan salah satunya untuk dipasang di tiga bengkel Jurusan Teknik Sipil dan Perencanaan, yaitu bengkel plambing, bengkel kayu, dan bengkel batu yang digunakan oleh mahasiswa semester I, II, dan IV. Pengkajian pemanfaatan poster di bengkel ini nantinya dapat digunakan sebagai dasar dalam mendesain dan membuat poster agar dapat berfungsi secara maksimal. Desain dan pembuatan poster tersebut nantinya akan dilakukan mahasiswa dengan bimbingan peneliti sebagai tenaga pengajar mata kuliah Media Pembelajaran dan Teknologi Informasi.

Penelitian ini menggunaan pendekatan deskriptif (descriptive reasearch). Peneliti mendeskripsikan secara ilmiah tentang penggunaan media pembelajaran terutama poster di bengkel Jurusan Pendidikan Teknik Sipil dan Perencanaan FT UNY. Dalam penelitian ini, peneliti tidak memberikan perlakuan terhadap apa yang diteliti tetapi hanya sebatas mendeskripsikan secara detail terhadap apa yang ditemukan dalam pengambilan data. Penelitian ini dilakukan di lingkungan Jurusan Pendidikan Teknik Sipil dan Perencanaan (PTSP) Fakultas Teknik (FT) Universitas Negeri Yogyakarta (UNY) terutama di laboratorium komputer, bengkel plambing, bengkel kayu, dan bengkel batu. Peneliti memperoleh data dari responden, yaitu mahasiswa semester $\mathrm{V}$ yang mengikuti mata kuliah Media Pembelajaran dan Teknologi Informasi. Pada semester tersebut mahasiswa telah menerima materi mengenai poster. Selain itu, peneliti juga melakukan observasi secara langsung ke tiga bengkel tersebut. Metode pengumpulan data dalam 
penelitian ini menggunakan observasi dan angket.

Observasi dilakukan langsung ke bengkelbengkel yang ada di Jurusan Teknik Sipil dan Perencanaan FT UNY. Selain itu, data juga didapatkan dari angket mengenai pemanfaatan poster di bengkel Jurusan Pendidikan Teknik Sipil dan Perencanaan yang diberikan kepada responden. Data dalam angket tersebut menggunakan skala Likert. Instrumen penelitian disusun berdasarkan kiri-kisi instrumen yang meliputi unsur-unsur yang dipersyaratkan untuk suatu poster yang baik (tema dan tujuan, bahasa, tampilan, ukuran, warna); pemanfaatan (visualisasi ide, ekonomis); dan kesesuaian (fungsi, kemudahan ketika dilihat). Instrumen ini berbentuk angket pernyataan skala Likert yang diisi mahasiswa. Angket tersebut diisi oleh 90 mahasiswa secara acak untuk semua bengkel. Pemilihan mahasiswa semester $\mathrm{V}$ didasarkan pada pertimbangan bahwa mahasiswa pada semester tersebut sedang mengikuti mata kuliah Media Pembelajaran dan Teknologi Informasi.

\section{HASIL DAN PEMBAHASAN}

Peneliti melakukan observasi secara langsung di tiga bengkel Pendidikan Teknik Sipil dan Perencanaan FT UNY, yaitu di bengkel kayu, bengkel plambing, dan bengkel batu. Dalam observasi tersebut, peneliti juga melakukan wawancara dengan teknisi bengkel. Dalam observasi yang dilakukan di bengkel kayu, peneliti melihat sekitar dua belas poster. Dari dua belas poster tersebut lima diantaranya sudah lama dan warna mulai pudar. Warna poster tersebut sudah kurang menarik lagi. Sementara itu hasil observasi yang telah dilakukan di bengkel plambing, terdapat sekitar sembilan buah poster dengan kondisi lima poster masih baru dan empat poster sudah lama. Poster yang sudah lama tersebut keadaan warnanya sudah mulai pudar. Sedangkan hasil observasi yang dilakukan di bengkel batu, terdapat lima poster yang masih baru. Poster di bengkel batu dikonsentrasikan di ruang teori.
Indikator tema dan tujuan poster di bengkel kayu mendapatkan nilai 3.69 dan masuk dalam kategori baik. Hal ini berarti bahwa poster-poster yang terdapat di bengkel kayu mempunyai tujuan dan tema yang jelas sesuai dengan maksudnya. Penempatan poster mengenai pemakaian alat pemotong kayu didekatkan dengan alat pemotong kayu. Indikator bahasa poster di bengkel kayu mendapatkan nilai 3,62 dan masuk dalam kategori baik. Hal ini berarti bahasa yang digunakan dalam poster-poster di bengkel kayu dapat tersampaikan kepada penerima pesan. Bahasa yang digunakan singkat, padat, dan jelas. Indikator penampilan poster di bengkel kayu mendapat nilai 3,65 dan masuk dalam kategori baik. Penampilan secara umum poster-poster yang terdapat di bengkel kayu baik dan sesuai dengan lingkungan bengkel. Indikator ukuran dan warna poster di bengkel kayu mendapat nilai 3,50 dan masuk dalam kategori baik. Apabila dilihat dari ukuran, poster-poster tersebut sudah cukup besar. Dari segi warna, poster-poster mempunyai warna yang serasi dengan lingkungannya. Indikator informatif yang terkandung dalam poster-poster di bengkel kayu mendapat nilai 3,58 dan masuk kategori baik. Poster-poster di bengkel kayu sudah dapat digunakan untuk menyampaikan pesan kepada penerima sesuai maksudnya. Walaupun beberapa poster tidak banyak menggunakan kata-kata tetapi pesan yang terdapat dalam gambar poster sudah dapat tersampaikan. Indikator ekonomis poster di bengkel kayu mendapat nilai 3,63 dan masuk dalam kategori baik. Apabila dilihat dari nilai poster yang terkandung dalam tampilannya maka posterposter di bengkel kayu sudah sesuai dengan pembuatannya. Bahan pembuatan poster dapat disesuaikan agar tidak terlalu mahal. Indikator kesesuaian poster di bengkel kayu mendapat nilai 3,83 dan masuk dalam kategori baik. Hal tersebut menandakan bahwa poster-poster di bengkel kayu sudah sesuai dengan fungsi poster itu sendiri yaitu menyampaikan pesan sesuai maksudnya. Poster berupa gambar jenis sambungan diletakkan dibagian tengah bawah agar dalam melihat tidak terlalu sulit. Sementara itu, anjuran untuk memperhatikan keselamatan dan kesehatan kerja (K3) diletakkan dibagian 
tengah atas ruangan agar mudah terlihat. Indikator kemudahan terlihat poster di bengkel kayu mendapat nilai 3,33 dan masuk dalam kategori cukup baik. Hal ini menandakan bahwa penerima pesan masih perlu usaha lebih untuk melihat poster. Poster belum terlihat secara jelas apabila dilihat secara sekilas. Penerima pesan harus mendekat ke poster agar terlihat dengan jelas. Beberapa poster berukuran tidak terlalu besar diletakkan didekat peralatan. Selain perolehan data diatas, responden juga memberikan komentar lain yang diantaranya adalah penggantian poster yang usang, penempatan poster pada tempat yang mudah terlihat, dan font pada poster dibuat lebih besar agar mudah terbaca.

Sementara itu, indikator tema dan tujuan poster di bengkel plambing mendapat nilai 3,79 dan masuk dalam kategori baik. Poster-poster di bengkel ini sudah disesuaikan antara isi dan lingkungannya. Poster berupa pemakaian alat pelindung diri dalam mengelas menggunakan las listrik telah didekatkan pemasangannya dengan mesin las listrik. Indikator bahasa poster di bengkel plambing mendapat nilai 3,52 dan masuk dalam kategori baik. Hal demikian berarti bahasa yang digunakan dalam poster-poster di bengkel plambing mudah dimengerti. Penggunaan bahasa yang singkat dan jelas sangat membantu dalam menerima pesan. Indikator penampilan poster di bengkel plambing mendapat nilai 3,56 dan masuk dalam kategori baik. Secara umum, tampilan posterposter yang terdapat di bengkel plambing sudah sesuai dengan lingkungan sekitarnya. Indikator ukuran dan warna di bengkel plambing mendapat nilai 3,38 dan masuk dalam kategori cukup baik. Keadaan beberapa poster-poster di bengkel plambing terutama warnanya sudah mulai pudar. Hal tersebut karena poster sudah lama walaupun maksudnya masih tersampaikan. Indikator informatif di bengkel plambing mendapat nilai 3,51 dan masuk dalam kategori baik. Hal ini berarti informasi dari poster yang terdapat di bengkel plambing sudah dapat tersampaikan. Indikator ekonomis poster di bengkel plambing mendapat nilai 3,55 dan masuk dalam kategori baik. Hal tersebut berarti bahwa nilai ekonomis poster sudah sesuai dalam penggunaannya. Indikator kesesuaian dengan fungsi poster di bengkel plambing mendapat nilai 3,71 dan masuk dalam kategori baik. Kesesuaian poster dengan maksudnya sudah dapat tersampaikan. Indikator kemudahan poster di bengkel plambing untuk terlihat mendapat nilai 3,32 dan masuk kategori cukup baik. Beberapa poster masih kurang tepat peletakannya apabila dikaitkan dengan lingkungannya. Selain perolehan data diatas, responden juga memberikan komentar lain yang diantaranya adalah pembaharuan poster yang usang serta penempatan poster agar lebih mudah terlihat.

Sedangkan indikator tema dan tujuan poster di bengkel batu mendapat nilai 3,80 dan masuk dalam kategori baik. Poster-poster yang terdapat di bengkel batu sudah sesuai dengan maksud poster itu sendiri. Indikator bahasa poster di bengkel batu mendapat nilai 3,41 dan masuk dalam kategori baik. Penggunaan bahasa dalam poster mudah dimengerti oleh penerima pesan. Indikator penapilan poster di bengkel batu mendapat nilai 3,48 dan masuk dalam kategori baik. Poster-poster yang terdapat di bengkel batu relatif baru sehingga terlihat masih baik. Indikator ukuran dan warna poster di bengkel batu mendapat nilai 3,48 dan masuk dalam kategori baik. Selain ukuran poster yang relatif besar, penggunaan warna poster di bengkel batu juga menarik. Indikator informatif poster di bengkel batu mendapat nilai 3,68 dan masuk dalam kategori baik. Pesan yang terkandung didalam poster di bengkel batu mampu diterima dengan baik. Indikator ekonomis poster di bengkel batu mendapat nilai 3,65 dan masuk dalam kategori baik. Pembuatan poster sudah sesuai dengan maksud dan kualitas, selain itu juga mempunyai nilai ekonomis. Indikator kesesuaian dengan fungsi poster di bengkel batu mendapat nilai 3,66 dan masuk dalam kategori baik. Hal tersebut berarti maksud poster sudah tersampaikan dengan baik. Indikator kemudahan untuk terlihat poster-poster yang terdapat di bengkel batu mendapat nilai 3,43 dan masuk dalam kategori baik. Hal ini karena keberadaan poster di bengkel batu dikonsentrasikan di ruang teori saja. 
Hasil perhitungan pada masing-masing indikator setiap faktor di bengkel kayu, bengkel plambing, dan bengkel batu diatas apabila direkap sebagai berikut:

Tabel 1. Kategori Penilaian Indikator Setiap Bengkel

Tabel 1. Kategori Penilaian Indikator Setiap Bengkel

\begin{tabular}{clccc}
\hline Faktor & \multicolumn{1}{c}{ Indikator } & Bengkel Kayu & Bengkel Plambing & Bengkel Batu \\
\hline Prasyarat & Tema dan Tujuan & Baik & Baik & Baik \\
& Bahasa & Baik & Baik & Baik \\
& Penampilan & Baik & Baik & Baik \\
& Ukuran dan Warna & Baik & Cukup Baik & Baik \\
\multirow{5}{*}{ Kemanfaatan } & Informatif & Baik & Baik & Baik \\
& Ekonomis & Baik & Baik & Baik \\
Kesesuaian & Sesuai dengan Fungsi & Baik & Baik & Baik \\
& Mudah Terlihat & Cukup Baik & Cukup Baik & Baik \\
\hline
\end{tabular}

Sementara itu, hasil analisa perolehan data yang didapatkan melalui angket adalah sebagai berikut. Uji validitas dilakukan untuk mengetahui validnya instrumen yang digunakan. Dalam uji validitas ini, diuji 20 butir pernyataan dengan jumlah responden $90 \quad(\mathrm{~N}=90)$. Data tersebut dinyatakan valid apabila $\mathrm{r}$ tabel yang diperoleh dengan taraf signifikansi $1 \%$ adalah diatas 0,2673 . Dari data yang diperoleh setelah diuji validitasnya menggunakan SPSS versi 22 didapatkan semua skor berada diatas 0,2673. Berdasarkan hasil tersebut dapat disimpulkan bahwa 20 butir pernyataan yang digunakan dalam angket dinyatakan valid. Selain uji validitas diatas, butir pernyataan juga diuji reliabilitasnya. Uji reliabilitas ini juga menguji 20 butir pernyataan dengan jumlah responden 90 $(\mathrm{N}=90)$. Data tersebut dinyatakan reliabel apabila $r$ tabel yang diperoleh dengan taraf signifikansi $1 \%$ adalah diatas 0,2673 . Dari data yang diperoleh setelah diuji reliabilitasnya menggunakan SPSS versi 22 didapatkan skor 0,879 . Berdasarkan hasil tersebut dapat disimpulkan bahwa 20 butir pernyataan dinyatakan reliabel atau terpercaya.

Hasil observasi terkait kondisi poster yang terdapat di bengkel kayu, bengkel plambing, dan bengkel batu adalah sebagai berikut. Sebagian besar poster sudah baik, hanya ada poster yang perlu pembaharuan karena sudah usang sehingga sudah tidak menarik lagi untuk dilihat. Peletakan poster yang terlalu tinggi membuat poster tersebut kurang terlihat karena ukuran tulisan yang kecil. Sedangkan hasil angket yang diisi mahasiswa mengenai prasyarat, kemanfaatan, dan kesesuaian poster yang berada di bengkel kayu, bengkel plambing, dan bengkel batu Jurusan Pendidikan Teknik Sipil dan Perencanaan FT UNY sebagian besar sudah baik. Hal tersebut dibuktikan dengan komentar dan skor yang diberikan mahasiswa yang terdapat pada angket. Meskipun masih perlu adanya pembaharuan poster yang sudah usang, bahasa yang digunakan dalam poster sudah singkat dan jelas. Ukuran font pada poster harus besar agar mudah terbaca. Selain itu tata letak poster harus mudah terlihat.

Di bengkel kayu, sebagian besar indikator poster yang terdapat pada bengkel kayu masuk dalam kategori baik kecuali kemudahan untuk terlihat. Dari hal tersebut dapat diinterpretasikan bahwa responden menganggap bahwa prasyarat dan kemanfaatan poster sudah baik, hanya saja kemudahan poster untuk terlihat masih kurang. Hal tersebut dikarenakan di poster di bengkel kayu diletakkan di dinding bagian atas. Keadaan 
poster yang sudah usang dan font yang kecil membuat beberapa poster sulit untuk dibaca.

Di bengkel plambing, indikator poster yang terdapat di bengkel plambing sebagian besar masuk dalam kategori baik. Hanya pada indikator ukuran dan warna poster serta kemudahan untuk terlihat masuk dalam kategori cukup baik dikarenakan poster yang ada di bengkel plambing banyak yang sudah usang sehingga warna yang terlihat kurang menarik.

Sementara itu, hasil analisa perolehan data yang didapatkan melalui angket adalah sebagai berikut. Uji validitas dilakukan untuk mengetahui validnya instrumen yang digunakan. Dalam uji validitas ini, diuji 20 butir pernyataan dengan jumlah responden $90(\mathrm{~N}=90)$. Data tersebut dinyatakan valid apabila $r$ tabel yang diperoleh dengan taraf signifikansi $1 \%$ adalah diatas 0,2673. Dari data yang diperoleh setelah diuji validitasnya menggunakan SPSS versi 22 didapatkan semua skor berada diatas 0,2673. Berdasarkan hasil tersebut dapat disimpulkan bahwa 20 butir pernyataan yang digunakan dalam angket dinyatakan valid.

Selain uji validitas diatas, butir pernyataan juga diuji reliabilitasnya. Uji reliabilitas ini juga menguji 20 butir pernyataan dengan jumlah responden $90(\mathrm{~N}=90)$. Data tersebut dinyatakan reliabel apabila $r$ tabel yang diperoleh dengan taraf signifikansi $1 \%$ adalah diatas 0,2673. Dari data yang diperoleh setelah diuji reliabilitasnya menggunakan SPSS versi 22 didapatkan skor 0,879 . Berdasarkan hasil tersebut dapat disimpulkan bahwa 20 butir pernyataan dinyatakan reliabel atau terpercaya.

Berdasarkan hasil dan pembahasan dalam penelitian ini dapat disimpulkan bahwa (1) Poster telah dimanfaatkan sebagai media pembelajaran baik di bengkel kayu, bengkel
Di bengkel batu, berdasarkan hasil angket di bengkel batu untuk semua indikator dalam kategori baik. Hal ini dapat dilihat karena poster di bengkel batu sudah banyak mengalami pembaharuan. Hanya saja berdasarkan masukan dari responden, poster hendaknya juga diletakkan pada tempat praktik sehingga tidak hanya pada ruang teori saja. Tetapi hal tersebut dimaklumi karena bila poster diletakkan di tempat praktik maka akan lebih mudah kotor.

\section{SIMPULAN}

Berdasarkan hasil dan pembahasan dalam penelitian ini dapat disimpulkan bahwa (1) Poster telah dimanfaatkan sebagai media pembelajaran baik di bengkel kayu, bengkel plambing, maupun bengkel batu. Poster digunakan untuk menyampaikan informasi alat pelindung diri, langkah kerja, bagian-bagian dari suatu alat, produk pembelajaran, maupun peringatan pentingnya Keselamatan dan Kesehatan Kerja. (2) Faktor prasyarat poster di bengkel kayu dan bengkel batu sudah terpenuhi. Hanya saja untuk prasyarat berupa indikator ukuran dan warna poster di bengkel plambing masih perlu ditingkatkan. Selain itu, faktor kesesuaian berupa indikator kemudahan poster untuk terlihat di bengkel kayu dan plambing juga perlu ditingkatkan. Indikator yang terdapat pada faktor prasyarat, kemanfaatan, dan kesesuaian lain yang terdapat di ketiga bengkel tersebut sudah terpenuhi. (3) Kesesuaian poster di bengkel kayu, bengkel plambing, dan bengkel batu di Jurusan Pendidikan Teknik Sipil dan Perencanaan FT UNY sudah baik. Poster sudah sesuai dengan fungsi dan maksud masingmasing bengkel. Hanya saja perlu adanya pembenahan dalam penempatan poster. 


\section{DAFTAR RUJUKAN}

Bretz, Rudy. (1971). A Taxonomy of Communication Media. Education Technology Publication. New Jersey: Englewood Cliffs

Hanif Firdaus. (2014). Penggunaan Media Poster sebagai Sumber Belajar IPS untuk Meningkatkan Kemampuan Berfikir Kreatif. Diambil dari http://repository.upi.edu/13563/3/S_IPS_ 1002248_Abstract.pdf pada 21 Maret 2016

Hendriyadi, Madewi Mulyanratna, \& Mitarlis. (2014). Penerapan Pembelajaran IPA Terpadu dengan Model Pembelajaran Kooperatif Tipe STAD Menggunakan Media Poster pada Tema Pemanasan Global Di SMP Negeri 2 Menganti Kabupaten Gresik. Jurnal Pendidikan Sains. Vol. 2 No. 01: hal 117-122

I Putu Arie Permana, Arwin Achmad, \& Berti Yolida. (2015). Penggunaan Poster melalui Model Pembelajaran Kooperatif STAD terhadap Aktivitas dan Hasil Belajar. Jurnal Bioterdidik. Vol. 3 No. 6: hal

Tim Pengembang Media Pembelajaran dan TI. 2015. Rencana Pembelajaran Semester. Yogyakarta: Fakultas Teknik UNY 